\section{Low back pain as an equivalent of neurogenic claudication in elderly patient: Case report}

\author{
Igor Borshchenko ${ }^{1,2 \star}$, Roman Kartavykh³, Andrey Baskov², \\ Andrey Grin² and Maria Borshchenko ${ }^{4}$ \\ ${ }^{1}$ N.V Sklifosovsky Research Institute of Emergency Medicine, Department of Healthcare, 3 Bolshaya \\ Sukharevskaya Square, Moscow 129090, Russia \\ ${ }^{2}$ Orthospine Clinic, Proyezd Beryozovoy Roshchy, 12, Moscow 125252, Russia
}

${ }^{3}$ Department of Nervous Diseases and Neurosurgery, RUDN, Miklukho-Maklaya Str., 8, 117198,

Moscow, Russia

${ }^{4}$ I.M. Sechenov First Moscow State Medical University, 8-2 Trubetskaya str., 119991, Moscow, Russia
Received: 12 June, 2020

Accepted: 24 June, 2020

Published: 25 June, 2020

*Corresponding author: Igor Borshchenko, N.V Sklifosovsky Research Institute of Emergency Medicine, Department of Healthcare, 3 Bolshaya Sukharevskaya Square, Moscow 129090, Russia, Tel: +7 499 9950862; Fax: +7 +7 499 4902863;

E-mail: borsh2001@gmail.com; Borsh2000@mail.ru

Keywords: Low back pain; Degenerative spinal stenosis; Neurogenic claudication; Case report

https://www.peertechz.com

\section{Check for updates}

\begin{abstract}
This clinical report presents the case of chronic low back pain in elderly female referring to multilevel (L2-L5) degenerative lumbar spinal stenosis without typical neurogenic claudication and leg pain. Subsequent minimally invasive surgical decompression produced complete resolve of the pain and drastic improvement life quality. This surgery confirmed the pain origin and proves the possibility of sole low back pain as an equivalent of neurogenic claudication. Considering this type of clinical pattern of spinal stenosis can direct general practitioner or other medical professional to correct diagnosis and prompt surgical treatment.
\end{abstract}

\section{Introduction}

Neurogenic claudication with severe leg pain and walking capacity restriction is the main sign of degenerative lumbar spine stenosis [1]. Usually the dominating leg pain combines with low back pain and is perceived by the patient as the complex sensation. At the same time low back mobility in flection/extension test can reveal full range of painless motion [2]. In some cases of degenerative spinal stenosis low back pain can be the prevailing and sole complaint without allusion of gait and leg problem [3]. Together with the preserved and pain free mobility of the lumbar spine such low back pain could be the obstacle of prompt diagnosis of the spinal stenosis. Consequently, misdiagnosis leads to avoiding effective spine decompression and the low life quality persists in the history of the patient. Considering low back pain as the possible equivalent of neurogenic claudication it enables general practitioner, neurologist and neurosurgeon to find the correct reason of disability and offer the elderly patient minimally invasive surgery solution [4].

\section{Case presentation}

Informed consent was obtained from all individual participants included in the study.

This report presents the case of the 79 years old female with chronic low back pain. No signs of leg pain or typical claudication represented in the history. The pain increased at physical activity and alleviated at rest. The pain persisted for 6 years with the waves of improvements but in the last year the disability became constant and restricted activity of the patient severely. NSAID medications, physical activity modification was ineffective. The assessment revealed flattened lumbar lordosis with painless full range of motion of lumbar spine. Neurologic examination found absence of Achilles reflexes with no sensational disturbances. Pain intensity according to Visual Analogy Scale (VAS-10) reached 8 points. MRI assessment discovered severe degenerative central and lateral canal stenosis due to facet joint and yellow ligament overgrowth at L4L5 level together with discs protrusions (Figure 1). 
Considering spinal stenosis as the main reason of low back pain together with the overall degenerative changes the patient underwent bilateral minimally invasive spine decompression via unilateral approach [5]. The surgery helped with the nerve irritations which manifested in resolution of low back pain. Its intensity decreased the next day to 2-3 points and in 6 months it was $0-1$ points. The patient resumed previous activity and was especially happy to do some gardening. The control MRI displayed the perfect spinal canal decompression with minimal spinal muscle affection (Figure 2). The control flexion/extension test in 6 months demonstrated absence of restriction of lumbar spine mobility (Figure 3).

\section{Discussion}

Back pain is the leading reason of disability especially in elderly population [6]. Spine degeneration progresses with ageing and affects different part of the spine segment as to intervertebral disc, facet joints, spine ligaments [7]. The origin of the low back pain can be discogenic, arthritic, myofascial pain or so called nonspecific when the source of the pain is not defined. Degenerative spine stenosis is combined entity but the most characteristic symptom of it is neurogenic claudication. The natural history of spinal stenosis has undulating pattern with periods of long remissions [8]. This makes the GPs and neurologists prefer conservative treatment and rarely consider

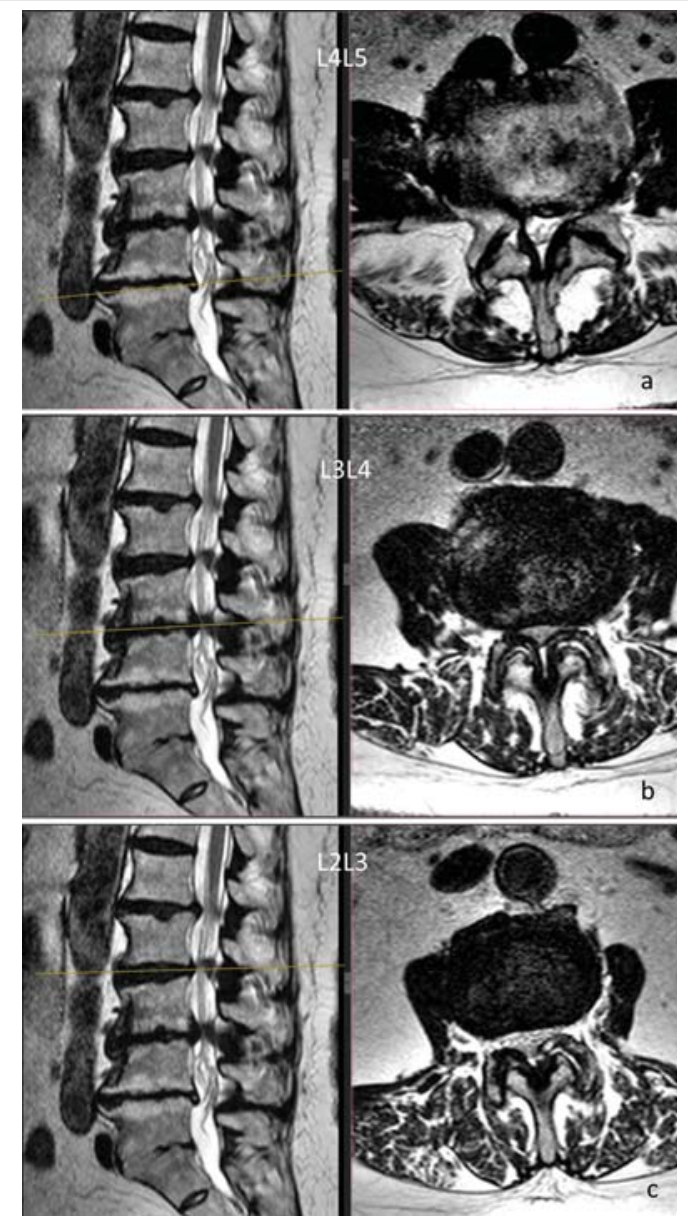

Figure 1: MRI of degenerative multilevel lumbar spinal stenosis before surgery. MRI reveals spinal degenerative stenosis due to overgrowth of facet joints, yellow ligaments and discs bulging at L4L5 (a), L3L4 (b), L2L3 (c) levels in female, 79 y.o.
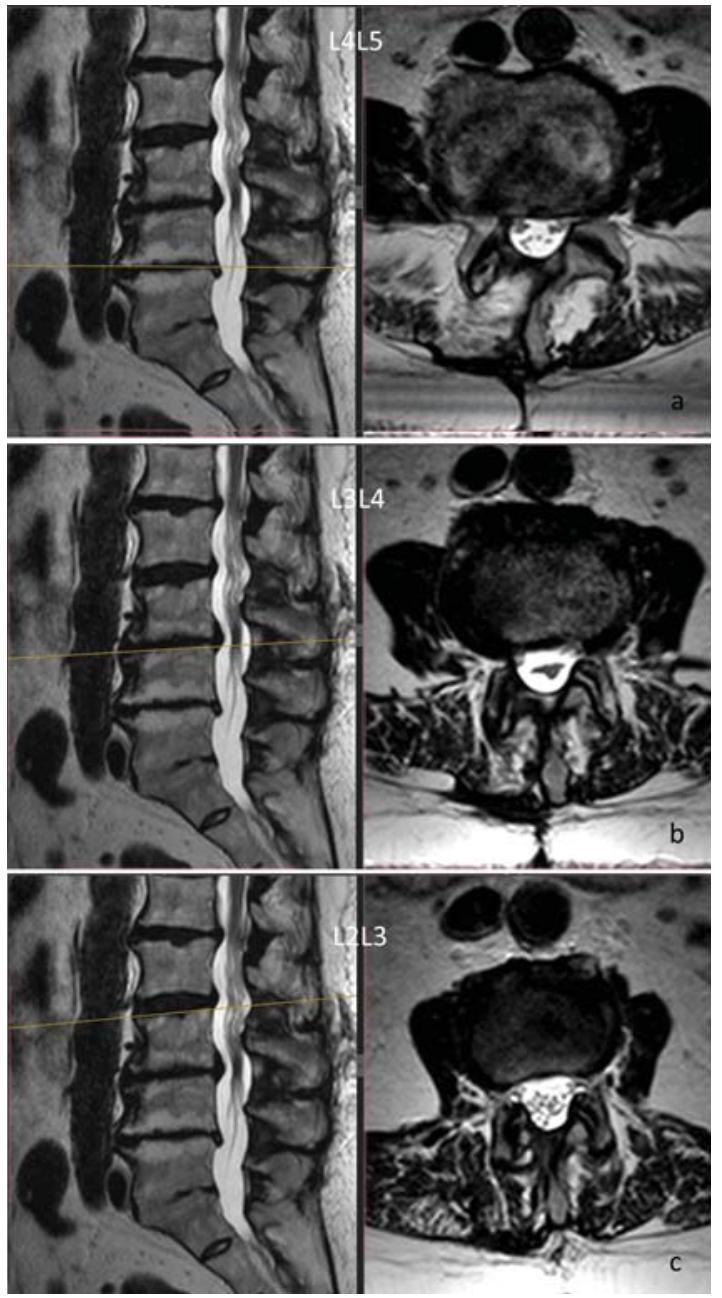

Figure 2: MRI of the same lumbar spine in 6 months after microsurgical decompression. MRI demonstrate perfect spinal canal reconstruction at L4L5 (a), L3L4 (b), L2L3 (c) levels using bilateral minimally invasive spine decompression via unilateral approach.

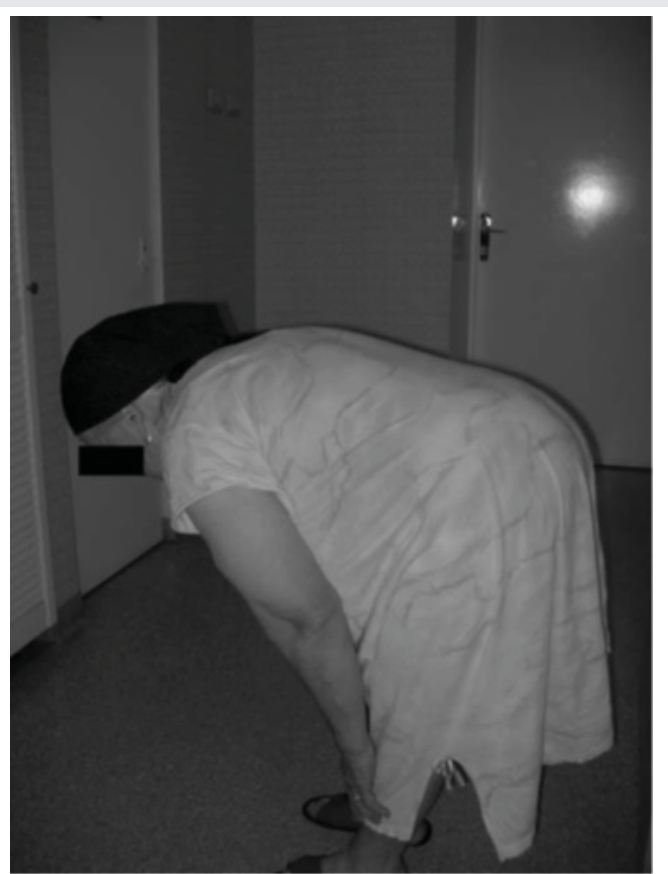

Figure 3: Flexion/extension test in 6 months after surgery. Flexion/extension test demonstrates persistent painless mobility both before and after surgical intervention. 
the surgery. Minimally invasive spine decompression surgical technique allows to reconstruct spinal canal and restore mobility with low perioperative risks [9].

Radicular pain can have classic pattern from lumbar spine along the leg or reside pattern when the pain spot localizes mostly in proximal part of dermatome or only in the back and buttock [10]. This explains the atypical presentation of pain in degenerative lumbar spine stenosis as sole low back pain. When knowing this clinical possibility, it can refer the patient and the medical doctor to the right diagnosis and avoid ineffective treatment of nonspecific back pain for years [11]. This observation proves the possibility of such clinical picture of spinal stenosis. The successful surgical treatment confirmed the supposition of pain origin as referred to spinal stenosis and demonstrated perfect clinical and radiological results.

\section{Conclusion}

Degenerative lumbar spine stenosis can produce atypical clinical pattern as sole low back pain that could be equivalent of neurogenic claudication in elderly patient. Prompt diagnosis of low back pain sours can offer the effective treatment including minimally invasive surgery.

\section{Ethical approval}

All procedures performed in studies involving human participants were in accordance with the ethical standards of Ethical Committee of the Ministry of health of the Russian Federation and with the 1964 Helsinki declaration and its later amendments or comparable ethical standards.

Informed consent: Informed consent was obtained from all individual participants included in the study.

\section{References}

1. Amundsen $T$, Weber $H$, Lilleås $F$, Nordal HJ, Abdelnoor M, et al. (1995) Lumbar spinal stenosis. Clinical and radiologic features. Spine 20: 1178-1186. Link: https://bit.ly/2Z7uyv0
2. Leinonen V, Määttä S, Taimela S, Herno A, Kankaanpää M, et al. (2003) Paraspinal muscle denervation, paradoxically good lumbar endurance, and an abnormal flexion-extension cycle in lumbar spinal stenosis. Spine 28: 324331. Link: https://bit.ly/3dxaLUe

3. Petersen T, Laslett M, Juhl C (2017) Clinical classification in low back pain: Best-evidence diagnostic rules based on systematic reviews. BMC Musculoskeletal Disorders 18. Link: https://bit.ly/2NmhcPv

4. Papavero L, Thiel M, Fritzsche E, Kunze C, Westphal M, et al. (2009) Lumbar spinal stenosis: Prognostic factors for bilateral microsurgical decompression using a unilateral approach. Neurosurgery 65: 182-187. Link: https://bit.ly/3dwAITQ

5. Spetzger $U$, Bertalanffy $H$, Reinges $M H$, Gilsbach JM (1997) Unilateral laminotomy for bilateral decompression of lumbar spinal stenosis. Part II: Clinical experiences. Acta Neurochir 139: 397-403. Link: https://bit.ly/319Ty0A

6. Hüllemann P, Keller T, Kabelitz M, Gierthmühlen J, Freynhagen R, et al. (2018) Clinical Manifestation of Acute, Subacute, and Chronic Low Back Pain in Different Age Groups: Low Back Pain in 35,446 Patients. Pain Pract 18: 1011 1023. Link: https://bit.ly/2zXsw1e

7. Eloqayli H (2018) Clinical Decision-Making in Chronic Spine Pain: Dilemma of Image-Based Diagnosis of Degenerative Spine and Generation Mechanisms for Nociceptive, Radicular, and Referred Pain. BioMed Res Int 2018: 8793843. Link: https://bit.ly/2Nmhhmf

8. Benoist M (2002) The natural history of lumbar degenerative spinal stenosis. Joint Bone Spine: Revue Du Rhumatisme 69: 450-457. Link: https://bit.ly/2B7mAmO

9. Machado GC, Ferreira PH, Harris IA, Pinheiro MB, Koes BW, et al. (2015) Effectiveness of Surgery for Lumbar Spinal Stenosis: A Systematic Review and Meta-Analysis. PLoS One 10: e0122800. Link: https://bit.ly/2VtiGvR

10. Kortelainen P, Puranen J, Koivisto E, Lähde S (1985) Symptoms and signs of sciatica and their relation to the localization of the lumbar disc herniation. Spine 10: 88-92. Link: https://bit.ly/3fP4AMX

11. Oliveira CB, Maher CG, Pinto RZ, Traeger AC, Lin CW, et al. (2018) Clinica practice guidelines for the management of non-specific low back pain in primary care: An updated overview. Eur Spine J 27: 2791-2803. Link: https://bit.ly/2B27HCg

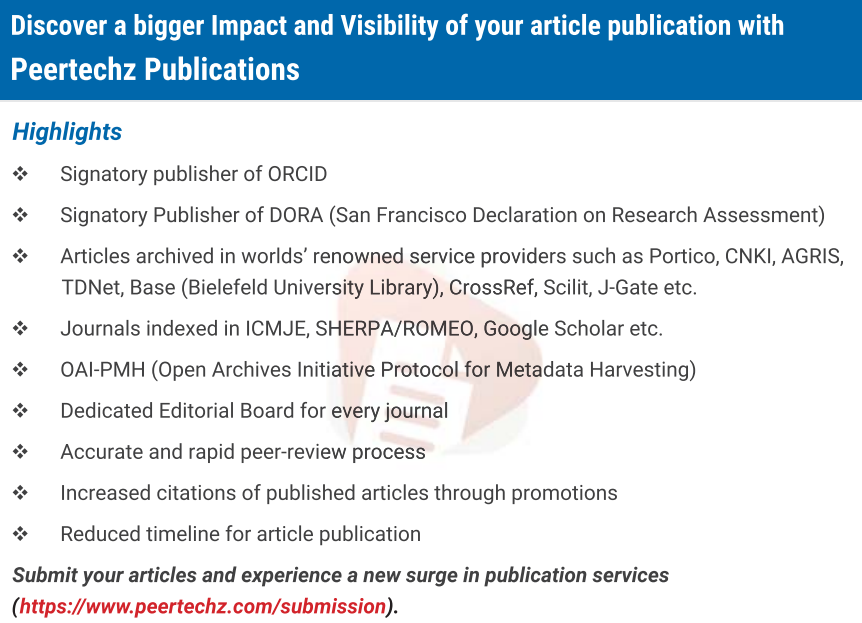

Copyright: @ 2020 Borshchenko l, et al. This is an open-access article distributed under the terms of the Creative Commons Attribution License, which permits unrestricted use, distribution, and reproduction in any medium, provided the original author and source are credited. 